\title{
REFLEXÕES SOBRE O CONSUMO SUSTENTÁVEL DA FAUNA MARINHA À LUZ DAS AUTUAÇ̃̃ES DO IBAMA NO CASO DA PESCA DAS LAGOSTAS NO CEARÁ
}

\author{
Reflections on the sustainable consumption of marine wildlife in the light of \\ ibama authorities in the case of lobster in ceará
}

Recebido: 15.06.2018 Aceito: 06.10.2018

Fábio Campelo Conrado de Holanda

Doutor em Ciência Política pela UFRGS. Mestre em Direito pela UFC. Graduado em Direito pela UFC. Professor do Programa de Mestrado em Direito da Uni7. Procurador Federal da AGU. E-mail: fabiodeholanda@yahoo.com.br Lattes: http:/ / lattes.cnpq.br/6078803341806941

\section{Francisco Dias de Oliveira Junior}

Mestre em Direito Privado pelo Centro Universitário 7 de Setembro. E-mail: fdoj2009@hotmail.com. Lattes: http:// lattes.cnpq.br/6635672552806717

Resumo: O presente trabalho se propõe a investigar a utilização dos animais não humanos no mercado de consumo e pela indústria brasileira, numa perspectiva de ética ambiental. A problemática da pesquisa é identificar se o comércio de produtos desenvolvidos com base em experimentos feitos pela indústria e a comercialização de produtos manufaturados utilizando animais não humanos como matéria prima, estaria se respeitando os limites admitidos pelas correntes de expansão da ética ambiental e, por conseguinte, em conformidade com as regras de sustentabilidade numa dimensão ecológica, com enfoque na legislação consumerista brasileira? A relevância do tema se manifesta tendo em vista a questão da dignidade humana perspectivada no comprometimento de espécimes da fauna marinha em diferentes territórios geográficos, ladeada pela análise do direito comparado. A metodologia utilizada é a qualitativa, envolvendo a análise bibliográfica disponível que esteja relacionada ao tema pesquisado.

Palavras-chaves: Animais não-humanos; experimentos na indústria; ética ambiental; mercado de consumo.

\begin{abstract}
Aвstract: This study aims to investigate the use of nonhuman animals in the consumer market and the Brazilian industry, an environmental ethics perspective. The issue of research is to identify whether: Product trade developed based on experiments done by the industry and the marketing of products manufactured using non-human animals as raw material, would be within the limits allowed by expansion of current environmental ethics and, therefore in accordance with the rules of sustainability in an ecological dimension, focusing on Brazilian consumerist legislation? This is a very important issue because it is concerned the dignity of those living beings. All these issues will be discussed in this article. The methodology used is qualitative, involving the available literature review related to the topic searched.
\end{abstract}

Keywords: Non-human animals; experiments in the industry; environmental ethics; consumer market. 
SUMÁRIO: Introdução. 1. Ética ambiental e os animais não-humanos. 2. Animais não-humanos, comércio, uso em práticas desportivas, experimentos científicos e na indústria manufaturada de alimentos, cosméticos, vestuário e acessórios: abolicionismo vs. Utilitarismo. 3. Análise do caso do atum rabilho e das autuações do IBAMA em relação à fauna marinha. 4. O Código do Consumidor brasileiro e a proteção do animal não-humano: desafios e possibilidades. 5. Uma incursão na normatização internacional concernente ao tema. Conclusão. Referências.

\section{INTRODUÇÃo}

Na medida em que a sociedade se conscientiza da importância de se fomentar uma ética ambiental, os demais ramos da "ciência do direito" passam a incorporar em seus discursos e normas a valoração ética das condutas em favor da preservação da fauna e da flora. Em relação às relações de consumo, por exemplo, tem-se observado progressivamente esta aderência do fornecimento de produtos e serviços com a dinâmica de preservação dos organismos vivos.

Sendo assim, a opção que se fez no presente arrazoado de debater as autuações do Instituto Brasileiro de Meio Ambiente e dos Recursos Naturais Renováveis (IBAMA) em relação à pesca da lagosta no Estado do Ceará (tradicional elemento da gastronomia e da economia local) serve ao propósito de debater empiricamente um discurso de transversalidade das normas jurídicas sob o prisma da eticidade, anunciando também uma gradual interseção das esferas pública (poder de polícia da Administração Ambiental) e privada (conscientização e mudança de postura no comércio de gêneros alimentícios extraídos do mar).

Propõe-se investigar, à luz do Código de Defesa do Consumidor (CDC), se a atividade econômica desenvolvida no Brasil em relação aos animais não-humanos teria atenção à perspectiva de sustentabilidade, visando o equilíbrio ecológico de acordo com as normas e princípios constitucionais. Teriam eles alguma proteção quanto aos cuidados que envolvem a sua comercialização e o uso em experimentos científicos pela indústria? Há no direito consumerista pátrio alguma norma que regulamente tais práticas? Em sendo afirmativa a resposta, estariam essas normas enquadradas dentro dos cânones que regem a ética ambiental e o ideal de sustentabilidade ecológica?

Existiria no Brasil alguma norma legal consumerista que exija do fabricante o uso de selos que identifiquem para o consumidor se determinada mercadoria possui procedência de experimentos feitos em animais não-humanos? Observam-se avisos de que determinada matéria prima para a confecção de bens de uso pessoal (a exemplo, de bolsas, sapatos, e até mesmo alimentos etc.) não provém do abate de animais não-humanos?

Com a promulgação da Constituição Federal de 1988, o meio ambiente passou a ter uma dimensão de direito fundamental de terceira geração de forma expressa em seu texto constitucional. A doutrina ambientalista vem assinalando o surgimento de um Novo Estado Socioambiental Democrático de Direito, que possui como pedra angular a defesa e a proteção do meio ambiente em todas as suas dimensões. 
Estabelecidas as premissas em epígrafe, é didático esclarecer que a metodologia a ser empregada nessa pesquisa será a qualitativa, levando em consideração, levantamento bibliográfico, doutrinário, jurisprudencial, assim, como monografias, artigos científicos que tratam das questões lançadas ao presente debate.

No primeiro tópico serão tecidas algumas considerações sobre a ética ambiental e os animais não-humanos; no segundo tópico, dando prosseguimento à pesquisa, será feita uma abordagem sobre o uso dos animais não-humanos no comércio, em práticas desportivas, experimentos científicos e na indústria manufaturada de alimentos, cosméticos, vestuário e acessórios, com ênfase no diálogo entre o abolicionismo e o utilitarismo; ao passo que no tópico seguinte, adentrar-se-á mais objetivamente no tema da pesquisa que tem como escopo o CDC brasileiro e a proteção do animal não-humano, com seus desafios e possibilidades. E por último, a conclusão do trabalho, tentar-se-á apresentar respostas aos questionamentos objeto da pesquisa, apontando algumas reflexões para a problemática a que se propôs investigar.

\section{2. ÉticA AMbiental E OS ANimAis NÃo humANOS}

Inicialmente, é de suma importância que se saiba que há forte corrente no sentido de defender que os animais não-humanos são seres que possuem a capacidade de experimentar a dor, a angústia, o sofrimento etc., dessa forma, não seria justo tratá-los como simples "objetos" ou "coisas" passíveis de serem utilizados em experimentos científicos e como matéria-prima para a fabricação de produtos manufaturados pela indústria brasileira.

Nos últimos trinta anos, tem-se observado a elevação das preocupações sociais sobre a conscientização da necessidade da proteção e da preservação do meio ambiente, de modo que o comércio de produtos feitos utilizando como matéria-prima a pele, as penas, os ossos e outras partes que compõe o corpo físico de determinadas espécies de animais não-humanos (a exemplo de crocodilos e avestruzes), tem sido criminalizado.

Nesse diapasão, as normas consumeristas têm se voltado para a proteção do meio ambiente por ocasião da regulação no fornecimento de bens e serviços, com relação ao tratamento dispensado aos animais não-humanos em conformidade com essa nova concepção de integridade e sustentabilidade ecológica defendida pela doutrina e pela ética ambiental, em consenso com o princípio do desenvolvimento sustentável como um fator de obtenção do justo equilíbrio entre as exigências da economia e as da ecologia.

A despeito da imprecisão do conceito de maus-tratos, pode-se recorrer à ética ambiental para se chegar a um entendimento da expressão, sendo que variados são os conceitos de "meio ambiente" para doutrina e jurisprudência. Para Gomes o ambiente como objeto, pode ser compreendido de acordo com três concepções, sendo a primeira a antropocêntrica, que "compreende os bens naturais como fontes de utilidade para a vida humana, como veículos de satisfação de necessidades vitais e de incremento do bem-estar"; uma segunda, que tende a "acentuar a necessidade de consideração da natureza como uma realidade só por si merecedora de tutela, independentemente da sua capacidade de satisfazer as exigências humanas"; e uma terceira, cujo viés identifica o ambiente com "um conceito indeterminado do tipo descritivo, em virtude da heterogeneidade dos seus componentes e da intensa inter-relação que nele se gera entre fatores em constante mudança". Abertura e 
relatividade caracterizariam, assim, o objeto jurídico indeterminado ambiente.

Na esteira do pensamento de Furlan e Fracalossi, o conceito de meio ambiente é normativo (teleologicamente biocêntrico, pois abriga a vida em todas as suas formas, mas ontologicamente ecocêntrico, pois alberga o conjunto de condições, leis, influências e interações de ordem química, física e biológica), pois a despeito do art. 225 da Constituição Federal não ter sido preciso na delimitação da expressão, soa razoável entender que tenha utilizado do conceito de meio ambiente contido na Lei 6.938/1981, que instituiu a Política Nacional do Meio Ambiente. Assim, segundo o autor, ter-se-ia um conceito de meio ambiente como patrimônio público e bem de uso comum do povo, entendido como "o conjunto de condições, leis, influências e interações de ordem física, química e biológica, que permite, abriga e rege a vida em todas as suas formas" (art. 3. $\left.{ }^{\circ}, \mathrm{I}\right)$.

De fato, da exegese do artigo 3. ${ }^{\circ}$, inciso I, da Lei 6.938/1981, verifica-se que é um conceito amplo, abrangendo todas as formas de vida existentes, contemplando nesse mesmo contexto as formas derivadas de meio ambiente, tais, como, o natural, o cultural, o laboral (do trabalho), o artificial (urbano) etc. Destaque-se, ademais, que a Constituição Federal não foi omissa quanto a proteção e a preservação das espécies da fauna brasileira, possuindo norma expressa nesse sentido, assim, como a proibição contra a crueldade, é o que diz o inciso VII, do artigo 225, caput, que traz a seguinte regulamentação: "proteger a fauna e a flora, vedadas, na forma da lei, as práticas que coloquem em risco sua função ecológica, provoquem a extinção de espécies ou submetam os animais a crueldade".

Ainda segundo a doutrina, para Antunes, o conceito de meio ambiente alberga o "humano como parte de um conjunto de relações econômicas, sociais e políticas que se constroem a partir da aproximação dos bens naturais que, por serem submetidos à influência humana, transforma-se em recursos essenciais para a vida humana". Na conformidade desse raciocínio, percebe-se que o homem é colocado no centro das relações econômicas, sociais e políticas com relação ao meio ambiente.

O Supremo Tribunal Federal (STF), na ADI-MC 3.540/DF, Rel. Min. Celso de Mello, em relação ao direito ao meio ambiente ecologicamente equilibrado, decidiu que é um típico direito de terceira geração, que assiste a todo o gênero humano, cabendo ao Estado e à própria coletividade, a especial obrigação de defender e preservar, em benefício das presentes e futuras gerações, esse direito de titularidade coletiva e de caráter transindividual.

Percebe-se, portanto, que os conceitos de meio ambiente ora apresentados possuem, de uma forma geral, uma visão antropocêntrica moderada, pois incluem todas as formas de vida como carecedoras de proteção (e não somente a humana, como professa a antropocentrista radical, defendido por Immanuel Kant, que colocava o homem como um ser superior aos demais seres existentes no planeta, em razão de ser o único ser capaz de decidir de acordo com a sua vontade, comparando as demais espécies a simples objetos ou coisas).

Para que se defina a relação humanos e não-humanos nesta perspectiva, é imprescindível o estudo das correntes da ética ambiental, e sobre a questão importante esclarecimento é fornecido por Medeiros, para quem "é impossível analisar as correntes da ética ambiental, a partir das tradicionais subdivisões entre o antropocentrismo radical (especistas) e o moderado; e as correntes sensocêntrica, biocêntrica e ecocêntrica". 
Segundo o referido autor, dentre as correntes antropocentristas (radical e moderada), coloca-se o ser humano como pertencente a uma categoria especial, sendo que a diferença entre ambas é que para a primeira a vida humana possui mais valor do que as das outras espécies. A outra vertente (adotada pela CF/1988 e pela Lei 6.938/81), admite que apesar de a vida humana possuir um valor moral de maior relevância, não se pode simplesmente desprezar a vida das demais espécimes, pois, todos fazem parte de um sistema integrado.

Esclarece, ainda, que o surgimento das correntes filosóficas expansivas da ética ambiental (sensocêntrica, biocêntrica e ecocêntrica), trouxe o entendimento de que os animais não-humanos são albergados pelo expansionismo ético ambiental, que passou a considerá-los como seres possuidores de relevante moral e assim como os humanos, sentem dor, angústia, frio, calor, alegria, tristeza e são capazes de experimentar todo e qualquer tipo de sofrimento.

Convém esclarecer que a ciência e a medicina veterinária atribuem essa capacidade de os animais não-humanos possuírem os mesmos sentimentos que o homem, pelo o fato deles apresentarem substratos neurais e um sistema nervoso límbico igual ao do homem, sendo esta a explicação cientifica que comprova serem os animais não-humanos seres sencientes.

Após pesquisas acadêmicas na área da neurociência foi descoberto que muitos animais não-humanos (inclusive os invertebrados, a exemplo, do polvo) possuem consciência, disto decorrendo que esses estados afetivos possuem grande relevância sob a perspectiva dos valores, haja vista estar provado que um animal pode sentir-se em pânico em determinadas situações que os coloquem em estado de extremo stress e medo. A propósito, em 7 de julho de 2012, foi elaborada na Inglaterra (Universidade de Cambridge), a Declaração de Cambridge sobre a Consciência, representando um marco no combate àquela filosofia antropocêntrica que retratava os animais não-humanos como "[...] máquinas e, consequentemente, utilizados como se assim fossem até meados do século $\mathrm{XX}$, quando emergiram diversos questionamentos sobre suas capacidades".

Estabelecida esta premissa científica, restou evidenciada a necessidade de se repensar várias práticas que ocorrem em nossa sociedade em relação aos animais, inclusive para que se possa lidar com as repercussões éticas das ações humanas, em uma sociedade que reconhece cada vez mais o estatuto moral dos animais.

Ainda no âmbito da neurociência, relata-se que um dos elementos que diferencia os animais humanos dos não-humanos é o QI social, ou seja, a capacidade que os humanos têm de entender o que outras pessoas pensam e sentem, a capacidade que só o homem possui de "compreender o comportamento passado de outras pessoas e prever como vão se portar diante de circunstâncias presentes e futuras".

Todavia, o mesmo autor pontua que a despeito de o comportamento social humano ser bem mais complexo que o de outras espécies, "há surpreendentes pontos em comum em certas características dos mamíferos se relacionarem entre si, observando-se na maioria deles o 'cérebro pequeno'", sendo de notar que na comparação com os humanos a parte deste "cérebro" responsável pelo pensamento consciente é relativamente pequena nos mamíferos não-humanos quando comparada à parte do cérebro envolvida nos processos inconscientes. Esclarece que "a organização do cérebro inconsciente é comum entre os mamíferos, sendo que alguns mecanismos neurais nos macacos, nos símios e até em mamíferos inferiores são semelhantes aos nossos, gerando comportamentos parecidos com os humanos". 
Após estas breves explanações verifica-se, pois, que existem elementos científicos que dão substrato para esse novo posicionamento das correntes filosóficas expansionistas da ética ambiental, que vêm modificando o paradigma antropocentrista.

\section{ANimais não humanos, COMÉrCio, USO EM PRÁticas desportivas, eXPERIMENTOS CIENTÍFICOS E NA INDÚSTRIA MANUFATURADA DE ALIMENTOS, COSMÉTICOS, VESTUÁRIO E ACESSÓRIOS: ABOLICIONISMO VS. UTILITARISMO}

A atividade econômica exercida no Brasil envolvendo a industrialização e o comércio e de produtos feitos a partir da matéria-prima animal é possível tendo em vista não existirem leis proibitivas nesse sentido. Isso decorre, possivelmente, da gênese antropocêntrica de algumas normas infraconstitucionais, que dispensam aos animais não-humanos a natureza jurídica de simples "coisas" ou "objetos", sem nenhum valor moral relevante.

O Código Civil brasileiro de 2002, no artigo 82 equipara os animais a simples objetos, desprezando totalmente o caráter senciente que possuem, dispensando-lhes uma natureza jurídica de bens móveis ao prescrever que: "São móveis os bens suscetíveis de movimento próprio, ou de remoção por força alheia, sem alteração da substancia ou da destinação econômico-social".

No entanto, tramita no Congresso Nacional o Projeto de Lei n ${ }^{\circ} 6.799 / 2013$, de autoria do deputado federal Ricardo Izar (SP), relacionado à alteração da redação do mencionado artigo 82, de modo a reconhecer os animais como seres sensíveis a emoções e sofrimento. Tal projeto teve a sua redação final aprovada pela Comissão de Constituição e Justiça. Registrese que a Constituição já prevê, em seu artigo 23, a proteção do meio ambiente e a preservação da fauna e da flora.

A propósito do viés consumerista do presente artigo, não se pode olvidar que apesar de o CDC brasileiro ser reconhecido como uma das leis mais modernas sobre a temática de proteção ao consumidor, no que se refere ao tratamento dado aos animais não-humanos, os tem como simples coisas ou objetos.

A prova disso, é que se alguém adquirir um animal de estimação doente ou se ele chegar a morrer por negligência no tratamento ou se vier a sofrer algum tipo de lesão que lhe cause a morte ou lhe deixe sequelas graves numa pet shop, seu proprietário terá que reclamar o acontecido com fundamento nos artigos do Código de Defesa do Consumidor (CDC), que tratam das relações de consumo. A responsabilidade civil nessa hipótese será com base na responsabilidade por danos patrimoniais nas relações de consumo e incidirá no caso, os artigos 18 a 25 da legislação consumerista que tratam das demandas entre fornecedor e consumidor com base nas relações de consumo envolvendo produtos ou serviços.

O animal de estimação que é considerado por muitas pessoas como um membro da família é tratado como um simples objeto pela legislação consumerista do Brasil, pois, perante a Lei brasileira os animais não-humanos, não são sujeitos de direitos e, assim, não lhes são atribuídos os direitos fundamentais de proteção à vida, dentre outros.

Advirta-se que, tais situações como as relatadas, não são tão incomuns de acontecer, merecendo inclusive um alerta por parte do PROCON São Paulo, conforme a notícia veiculada no Site do Estadão Economia e Negócios, informando aos consumidores que medidas devem tomar com relação aos seus animais de estimação: 
Fundação Procon-SP, órgão de defesa do consumidor ligado ao governo estadual, orienta o consumidor sobre os cuidados na compra de animais de estimação. Independentemente dos sentimentos que levam as pessoas a adquiri-los, o animal, para fins de enquadramento legal, é equiparado a um bem durável e, por isso, sua aquisição está sujeita às normas do Código de Defesa do Consumidor (CDC). [...] O Procon-SP recomenda o consumidor verificar, para sua maior segurança, se a loja está funcionando regularmente e se fornece todos os documentos que devem acompanhar o animal. Os documentos necessários são: a carteira de vacinação, o atestado médico veterinário e o pedigree, que garante a raça do animal. Os técnicos da entidade destacam que o consumidor deve exigir recibo ou nota fiscal com a descrição do animal, a data e o valor pago. [...] Se o animal de estimação tiver com alguma doença durante os primeiros 90 dias após a compra, o consumidor deve procurar a loja que, por sua vez, terá 30 dias para resolver a questão, alerta o ProconSP. Caso isso não ocorra, o consumidor tem, à sua livre escolha: o direito de solicitar a troca do animal por outro, em perfeitas condições; a devolução do valor pago; ou, se possível, o abatimento proporcional do preço. [...] O consumidor deve ficar atento também quando necessitar de serviços veterinários. De acordo com o Procon-SP, o serviço nunca pode estar vinculado à venda de produtos da própria clínica, pois isso se constitui em venda casada, prática considerada abusiva pelo Código de Defesa do Consumidor (CDC). [...] Se surgirem inflamações decorrentes da aplicação, ou contaminação pós cirúrgica (casos de castração, por exemplo,) o dono do animal pode recorrer a um órgão de defesa do consumidor se não conseguir entrar em acordo com a clínica. Já questões éticas podem ser encaminhadas ao Conselho Regional de Veterinária. (Grifo nosso).

A consequência prática que se pode tirar a partir das orientações do Procon-São Paulo, é que os animais não-humanos continuarão a receber um tratamento que os atribuem pouco ou nenhum valor moral, abrindo precedentes para que o segmento da sociedade que visa os lucros advindos com a fabricação, venda, uso e tantas outras formas de exploração animal, aconteça de forma indiscriminada, sem a observância das regras, normas e princípios que regem a preservação e a proteção do meio ambiente, indo de confronto com a CF/88, com a filosofia expansionista da ética ambiental e incompatível com o surgimento do Novo Estado Socioambiental Democrático de Direito, que vem ganhando adeptos na doutrina ambientalista.

Disto resulta, que o homem fica livre para fazer uso dos animais como sendo sua propriedade e deles podendo fazer o que melhor lhe convier, como vendê-los, trocá-los, sacrificá-los e até mesmo usá-los em práticas desportivas, a exemplo da vaquejada. Nesta prática, o boi poderia, por analogia, ser comparado a uma bola de futebol em campo, em que todos os jogadores a chutam de um lado para o outro, não importando a intensidade do chute ou os danos que venha a sofrer, pois, se trata de um simples objeto. Assim como a bola, o boi também sofre sérios danos durante uma vaquejada, como contusões, luxações, perda do rabo, etc., ocasionadas pela violência como é puxado e arremessado ao alto pelo vaqueiro, para que caia no chão deitado, a diferença é que o boi é um animal e como os humanos, possuidor de um sistema límbico que o torna sensível a dor, ao frio, ao calor, ao sofrimento e etc.

De certo, esta foi uma estranha comparação, mas a verdade é que os bois usados nas vaquejadas não passam de simples bolas de futebol em campo, o que muda é somente o objeto e a estrutura montada para a realização do esporte, no entanto, o mesmo tratamento que 
o boi recebe em uma pista de vaquejada, se analisadas ambas as condutas, analogicamente, é o mesmo que recebe uma bola em campo numa partida de futebol. Ao final, o balanço que se pode fazer, é que entre lucros e perdas, quem fica com as perdas é o boi, com efeito, sabe-se que num evento como a vaquejada, a soma em dinheiro que circula é avultosa e quem lucra com esses dividendos são os promotores do espetáculo de crueldade.

O mesmo ocorreu com as rinhas de galo e a farra do boi que em razão da crueldade e dos maus-tratos causados aos animais foram consideradas práticas inconstitucionais pelo Supremo Tribunal Federal.

Todos esses julgados são a prova de que os animais não-humanos vêm aos poucos sendo reconhecidos como seres sencientes e de acordo com o firmado na Declaração de Cambridge, nessa condição são carecedores de valor moral, dado que, não mais se admite sejam considerados como inclusos numa categoria que os iguala a simples objetos e coisas.

Vislumbra-se, nitidamente, que o importante para essas atividades desportivas e econômicas de uma forma geral envolvendo animais não-humanos são os lucros delas provenientes. Quanto ao meio ambiente, esse não importa, daí o resultante é a degradação ambiental, a comercialização ilegal e o tráfico de espécimes raras da fauna brasileira, muitas delas em extinção e que na maioria dos casos são comercializadas a preços exorbitantes, a exemplo, de algumas raças de cães vendidos em lojas de pet shops. De outro lado, vale lembrar, que existem os casos de alguns espécimes de animais que arrebatados de seu habitat de forma ilegal, são comercializados em feiras, praças, passeios de ruas, etc., a preços módicos no mercado interno informal, prática corriqueira no Brasil.

O Ibama como órgão fiscalizador dessas condutas ao tomar conhecimento da infração, faz a apreensão desses animais capturados clandestinamente e após uma triagem, os devolve ao seu habitat natural, vale dizer, levando-os para as áreas de preservação ambiental.

Entretanto, nem tudo está perdido, no tocante ao comércio, uso em experimentos científicos e na produção de bens de consumo e alimentos empreendidas relacionadas com o meio ambiente, na ADI-MC 3.540/DF de Relatoria do Min. Celso de Mello, do Supremo Tribunal Federal, firmou-se a seguinte jurisprudência, impondo as atividades econômicas desenvolvidas no Brasil, os ditames de proteção e preservação ambiental para a execução de empreendimentos que possuam alguma relação com o meio ambiente e a possibilidade de degradá-lo:

\section{A ATIVIDADE ECONÔMICA NÃO PODE SER EXERCIDA EM DESARMONIA

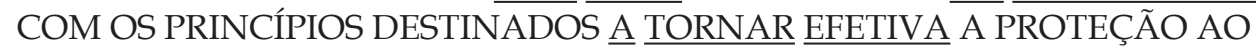 MEIO AMBIENTE.}

- A incolumidade do meio ambiente não pode ser comprometida por interesses empresariais nem ficar dependente de motivações de índole meramente econômica, ainda mais se se tiver presente que a atividade econômica, considerada a disciplina constitucional que a rege, está subordinada, dentre outros princípios gerais, àquele que privilegia a "defesa do meio ambiente" (CF, art. 170, VI), que traduz conceito amplo e abrangente das noções de meio ambiente natural, de meio ambiente cultural, de meio ambiente artificial (espaço urbano) e do meio ambiente laboral. Doutrina.

Os instrumentos jurídicos de caráter legal e de natureza constitucional objetivam viabilizar a tutela efetiva do meio ambiente, para que não se alterem as propriedades e os atributos que lhe são inerentes, o que provocaria inaceitável comprome- 
timento da saúde, segurança, cultura, trabalho e bem-estar da população, além de causar graves danos ecológicos ao patrimônio ambiental, considerado este em seu aspecto físico ou natural.

É justamente, nesse momento que se insurge nessa pesquisa a relevância em trazer ao espectro em estudo, o conhecimento das teorias abolicionista animal e a utilitarista defendida por Peter Singer. Na tentativa de trazer subsídios que justifiquem o não uso dos animais não-humanos em pesquisas cientificas, na produção de bens de consumo e a comercialização como simples objetos desprovidos de sentimentos, é necessário que se conheça o pensamento filosófico dessas correntes doutrinárias.

A luta em prol do "abolicionismo animal" já é uma realidade no Brasil, institutos abolicionistas animal, que são associações civis de caráter científico-educacional e sem fins lucrativos, a exemplo, do Instituto Abolicionista Animal (IAA), possuem como finalidade "defender a libertação dos animais não-humanos de toda forma de exploração ou crueldade praticada por seres humanos, utilizando-se de todos os meios legais e institucionais admitidos pelo ordenamento jurídico".

O Instituto Abolicionista Animal - IAA possui como objetivo:

Contribuir, através da educação, da conscientização e da capacitação em todos os níveis, para a abolição da exploração institucionalizada dos animais, em todas as suas formas: industrial, laboral, científica, cultural e comercial. Possibilitar aos animais o efetivo acesso às instâncias judiciais, através de representantes legítimos; contribuir para o aprimoramento e a eficácia social da legislação de proteção dos animais, e para a fundamentação ética de políticas públicas relacionadas à matéria.

Por essa posição, denota-se que os seguidores do abolicionismo animal são defensores ferrenhos em prol da abolição do uso de quaisquer espécies animais, seja pela indústria, no comércio, em experimentos científicos etc. Para os abolicionistas a vida desses seres é também alvo de grande relevância e valor moral. O ético nesse sentido, tem como preceito universal a preservação e a proteção dos animais não-humanos em todas as suas formas.

Já a teoria utilitarista de Singer possuí uma filosofia que leva em conta a ética como um valor universal e, por conseguinte, o princípio da igualdade seria aquele da igualdade de interesses, ou seja, importa dizer que seus próprios interesses, não podem ser mais importantes que os interesses dos outros, simplesmente, por serem os seus interesses. Dessa forma, chega-se à conclusão de que quando alguém se preocupa de maneira natural e ética para que seus interesses sejam levados em conta, esses devem ser estendidos aos interesses dos demais. Difere do utilitarismo clássico de Bentham e John Stuart Mill que possuía sua base teórica, fundada no prazer e no sofrimento. Vale dizer, que de uma forma ampla, a conquista de algo desejado corresponderia ao prazer, entretanto, caso ocorresse o contrário significaria sofrimento. 


\title{
Singer acreditava que:
}

[...] o princípio fundamental da igualdade, no qual se fundamenta a igualdade de todos os seres humanos, é o princípio da igual consideração de interesses. Só um princípio moral básico desse tipo pode permitir que defendamos uma forma de igualdade que inclua todos os seres humanos, com todas as diferenças que existem entre eles. [...] ao mesmo tempo que esse princípio proporciona uma base adequada para a igualdade humana, essa base não pode ficar restrita aos seres humanos. Em outras palavras, [...] aceito o princípio de igualdade como uma sólida base moral para as relações com outros seres de nossa própria espécie, também somos obrigados a aceitá-la como uma sólida base moral para as relações com aqueles que não pertencem à nossa espécie: os animais não-humanos.

Percebe-se que, como a teoria abolicionista, a utilitarista de Singer prega pela proteção e a preservação de todas as espécies de animais não-humanos, ambas, sustentando pontos de vista diferente, mas, convergindo em defesa da mesma causa, qual seja, o não uso dos animais não-humanos em práticas desportivas, na indústria, inclusive, a alimentícia, no comércio e em experimentos científicos.

\author{
Quanto ao uso dos animais na indústria alimentícia, Singer profere o seguinte \\ entendimento:
}

Para a maior parte das pessoas que vivem nas sociedades modernas e urbanizadas, a principal forma de contato com os animais acontece à hora das refeições. $\mathrm{O}$ uso de animais como alimento talvez seja a mais antiga e a mais difundida forma de uso animal. [...] a qual repousa a crença de que os animais existem para o nosso prazer e conveniência. Se os animais são importantes por si mesmos, o uso alimentar que deles fazemos torna-se questionável - sobretudo quando a carne animal é um luxo, e não uma necessidade. [...] Os cidadãos das sociedades industrializadas podem facilmente conseguir alimentação adequada sem que seja preciso recorrer à carne animal. O peso avassalador do testemunho médico indica que a carne animal não é necessária para boa saúde ou a longevidade. Além disso, a produção animal nas sociedades industrializadas não constitui uma forma eficaz de produção de alimentos, visto que a maior parte dos animais consumidos foi engordada com grãos e outros alimentos que poderíamos ter comido diretamente.

\section{Singer, desta feita, em defesa do não uso de animais não-humanos em experimentos científicos:}

[...] tais experiências quase sempre tentam justificar a sua realização com animais com a alegação de que as experiências nos levam a descobertas sobre os seres humanos; se assim for, essas pessoas devem concordar com a afirmação de que os seres humanos e os animais são semelhantes em aspectos cruciais. Por exemplo: se o fato de forçar um rato a escolher entre morrer de fome e atravessar uma grade eletrificada para conseguir comida nos diz alguma coisa sobre as reações dos seres humanos ao estresse, devemos admitir que o rato sente estresse quando colocado nesse tipo de situação. As pessoas às vezes pensam que as experiências com animais atendem a objetivos médicos vitais e podem ser justificadas com base no fato de que 
aliviam mais sofrimento do que provocam. Essa confortável crença não passa de um engano, os laboratórios testam novos xampus e cosméticos que estão pretendendo comercializar pingando soluções concentradas desses produtos nos olhos dos coelhos, num teste conhecido como " teste de Draize". ([...] Um teste alternativo, que não usa animais foi descoberto a pouco. Mesmo assim, ainda são muitas as indústrias, e dentre elas as maiores do ramo, que continuam a fazer o teste Draize).

Perceptível é a desnecessidade do uso de animais não-humanos em experimentos científicos, porquanto, mesmo que não houvesse outro método alternativo para as descobertas de curas de doenças nos humanos, nada justifica o sofrimento, a dor, a angústia, a mutilação causada nesses animais, em virtude desses procedimentos.

Grupos de ativistas em prol do meio ambiente vêm lutando incessantemente no combate a essas práticas e com sucesso em inúmeros casos, abolindo os animais nãohumanos dessa forma de tortura, caracterizado como o crime de maus-tratos tipificado pela Lei brasileira de Crimes Ambientais.

O mesmo se diga, quanto ao uso de animais não-humanos pela indústria de vestuários e acessórios, não se concebe mais no atual estágio em que o planeta se encontra, de extrema degradação ambiental e extinção de milhares de espécimes animais, que ainda sejam produzidos casacos, bolsas, cintos e sapatos com matéria prima de origem animal.

Uma gestão ambiental sustentável com o desenvolvimento de técnicas e ações que definam as atividades do homem visando suprir suas necessidades, sem que seja necessário colocar a prova a integridade do meio ambiente, já é uma realidade. Levando-se em consideração a sustentabilidade como o suporte que deve se atrelar o desenvolvimento econômico, usando-se de recursos naturais de forma inteligente e seguindo parâmetros de preservação ambiental já positivados nas leis infraconstitucionais, nos Tratados internacionais e na Constituição do Brasil de 1988.

São regras a serem seguidas por todos que se sentem responsáveis pelo meio ambiente. Esses são os novos caminhos para garantir a humanidade um desenvolvimento sustentável, com a responsabilidade ambiental como um preceito fundamental que assegura a proteção e a preservação do meio ambiente ecologicamente equilibrado para as gerações presentes e futuras.

\section{Análise do caso do atum rabilho e das autuações do ibama em relação À FAUNA MARINHA}

É comum que durante o mês de janeiro (época das férias e alta estação nas cidades litorâneas do nordeste brasileiro) ocorram autuações do IBAMA decorrentes de fiscalizações durante o período de defeso das espécies pargo, lagosta e caranguejo. Em determinados casos, a autarquia ambiental se dirige aos estabelecimentos de comércio de pescados, vistoriando as câmaras de refrigeração para identificar a origem do estoque e este é o mote de inúmeras autuações. 
Quando se identificam irregularidades, na esteira dos artigos 70, $\$ 1^{\circ}$ e 72 da Lei 9.605/1998 (que dispõe sobre as sanções penais e administrativas derivadas de condutas e atividades lesivas ao meio ambiente), cumulado com o artigo $3^{\circ}$ (que prevê as infrações administrativas) e 35 (que prevê a conduta típica de pescar em período ou local no qual a pesca seja proibida) do Decreto Federal $n^{\circ}$ 6.514/2008 a autarquia ambiental indiscutivelmente contribui para a paulatina conscientização do consumo sustentável de tais espécimes.

Da análise de alguns processos administrativos que tramitam na entidade (02007.000306/2018-69; 02007.000094/2018-10; 02007.000306/2018-69; 02007.000306/201869; 02007.000319/2018-38; 02007.000351/2018-13, dentre outros), extrai-se, por vezes, que as características das infrações dessa modalidade contemplam pessoas de baixa escolaridade, com infrações variando entre o pequeno e o médio impacto ambiental e, em grande medida, capitaneadas por proprietários de restaurantes em parceria com pescadores sem licença de pesca.

Acerca das reflexões que a sociedade tem feito sobre a eticidade da conduta humana no trato com os animais não-humanos que habitam os oceanos, tem-se interessante caso abordado no direito comparado acerca do papel do consumidor na preservação do atumrabilho do Atlântico.

Segundo artigo científico da lavra de Dawn M. Kato, a organização denominada The International Commission for the Conservation of Atlantic Tunas (ICCAT) supervisiona a conservação do atum-rabilho do Atlântico, existindo uma preocupação generalizada de que os esforços da ICCAT não tenham sido bem-sucedidos na proteção desta espécie. Segundo o mencionado artigo:

[...] muitos clientes de sushi podem não estar cientes, no entanto, da crescente preocupação mundial com a sobrevivência do atum-rabilho. A pesca predatória fez com que a população de atum-rabilho diminuísse em pelo menos noventa por cento nos últimos trinta e cinco anos, mas ainda assim os restaurantes de sushi continuam a ignorar a ameaça de extinção da espécie. A redução na demanda do consumidor poderia salvar esse peixe, mas os clientes de sushi continuam solicitando repetidamente o atum-rabilho.

Segundo o referido estudo, enquanto os consumidores de sopa de barbatana de tubarão encontram imagens horripilantes de populações de tubarões mutiladas e esgotadas, os consumidores de atum-rabilho continuam a vê-los como a principal experiência de sushi e não enfrentam tais imagens. $\mathrm{O}$ atum-rabilho é abundante, e a noção de que nossos oceanos contêm recursos ilimitados continua a vitimizar esta espécie de peixe. Assim, o consumidor segue desinformado e inconsciente da situação de ameaça de extinção dessa espécie, que continua a ser reverenciado como o precioso indutor do mercado de sushi.

No caso específico do atum-rabilho, tem-se uma dificuldade peculiar em comparação com os múltiplos leading cases de pesca predatória da lagosta no litoral do Ceará. É que devido à natureza migratória do atum-rabilho, é necessário um elevado nível de cooperação internacional para que os esforços regulatórios sejam eficazes. O atum-rabilho é uma espécie migratória por natureza, com corpos simplificados que lhes permite viajar até cinquenta milhas por hora e cruzar oceanos em apenas algumas semanas. Infelizmente, os padrões migratórios do atum-rabilho, combinados com a tendência de nadar próximo à superfície 
da água, facilita para as frotas de pescadores rastreá-los e atingi-los. O nível de cooperação internacional necessário para o manejo dessa espécie resultou em muitas dificuldades relacionadas à supervisão regulatória.

Segundo o autor, existe nos Estados Unidos histórico de restabelecimento de espécie de peixe ameaçada de extinção:

[...] Os Estados Unidos já conseguiram sucesso em restabelecer uma espécie de peixe ameaçada de extinção. Na década de 1970, o robalo listrado enfrentou um declínio devastador de sua população. Em resposta, os cientistas conduziram estudos emergenciais e os resultados levaram o Congresso a aprovar o Atlantic Striped Bass Conservation Act. Essa ação resultou em uma recuperação animadora da população. Em 1982, o robalo listrado somava menos de dez milhões. No seu auge, em 2004, a espécie atingiu uma população de 70,8 milhões. Uma vez submetido à intensa pesca predatória, o robalo listrado somente alcançou números sustentáveis devido à implementação de rigorosos controles de gestão [...].

Percebe-se que em situação semelhante a do robalo listrado encontra-se o atumrabilho, necessitando da implementação de rigorosos controles de gestão, a exemplo do que ocorre atualmente nos Estados Unidos.

\section{UMA INCURSÃO NA NORMATIZAÇÃO INTERNACIONAL CONCERNENTE AO TEMA}

A Convenção sobre o Comércio Internacional de Espécies da Flora e da Fauna Selvagens Ameaçadas de Extinção (CITES) - assinada em março de 1973, em Washington, EUA, e entrou em vigor em 1975 - tem por objetivo controlar o comércio internacional de fauna e flora silvestres, exercendo controle e fiscalização especialmente quanto ao comércio de espécies ameaçadas, suas partes e derivados, com base num sistema de licenças e certificados.

A CITES tem sido fundamental para limitar o comércio de plantas e animais em risco de extinção. Mas, somente no início da década de 1990 os conservacionistas recorreram à CITES para proteger certas espécies de peixes comerciais como uma alternativa para a má gestão dessas espécies.

Por seu turno, em 1992, a Suécia propôs a colocação do atum-rabilho no Anexo 192 da CITES (listado no Apêndice I), ficando, portanto, proibido o comércio dessa espécie. Os países que se opunham à lista argumentavam que a gestão da ICCAT melhoraria os números e a proposta foi derrotada.

Logo, os ambientalistas se referiram a essa proposta como uma oportunidade de ouro para pôr fim à pesca predatória do atum-rabilho. Mas, infelizmente, muitos governos deixaram passar essa oportunidade e a oposição novamente derrotou a proposta. Assim, um futuro verdadeiramente sustentável para este peixe tornou-se inviável ante um mercado do atum-rabilho extremamente lucrativo assim como as pressões políticas por parte dos representantes dos pescadores e empresas de pescas. 


\subsection{A necessidade de Conscientização para o Consumo sustentável}

A alta demanda e o consumo exacerbado dessa espécie (atum-rabilho) prestes a extinção, aliado a gana das empresas de pesca, tornaram mal sucedidos os esforços no sentido de limitar a oferta desta espécie. Assim, os vários esquemas desenvolvidos para regular o fornecimento de atum-rabilho provaram ser ineficazes na proteção desta espécie, porque visavam apenas a oferta do "produto", mas não a sua demanda.

Desta forma, os esforços contínuos e até agora não bem sucedidos no sentido de limitar a oferta de atum-rabilho chamam a atenção para a necessidade de uma nova abordagem. Pois, os vários esquemas desenvolvidos para regular o fornecimento de atumrabilho provaram ser ineficazes na proteção desta espécie. Mas, focar apenas na oferta é ignorar a outra metade da equação. A demanda desempenha um papel igual no consumo excessivo de qualquer recurso e, sem demanda, o atum-rabilho não estaria enfrentando a extinção hoje.

Nenhum esforço no sentido de diminuir a demanda pelo consumo desta espécie (produto) terá o resultado desejado, senão for capaz de munir os consumidores de informações sobre o impacto ambiental e possíveis consequências de suas escolhas no mercado de consumo. Nesse sentido, a simples informação constante do rótulo ou menu de que o atum-rabilho é uma espécie ameaçada ou em perigo de extinção pode desencorajar o consumidor a consumi-lo. Afinal, estudos recentes mostram um aumento global na preferência do consumidor por rótulos de produtos que fornecem informações sobre o impacto ambiental deste.

Cabe ressaltar que a rotulagem ecológica surgiu da teoria de que ajudar os consumidores a tomar consciência do dano que causam poderá mudar seu comportamento de consumo. Assim, rotular ecologicamente um produto significa indicar suas consequências nocivas ao meio ambiente, o que incentiva compras sustentáveis de produtos e, por sua vez, fornece incentivo econômico para a conservação ambiental.

A rotulagem ecológica permite que o consumidor leve em consideração os impactos ao meio ambiente ao tomar decisões de compras e cria incentivos para que o mercado forneça produtos sustentáveis.

Nesse ínterim, a certificação ambiental tem o condão de complementar os programas de rotulagem ecológica, segundo os quais um produto obtém seu selo ecológico somente depois que uma organização certificada avalia e aprova os atributos sustentáveis deste produto. Entre as atividades pesqueiras, a certificação ambiental aborda o impacto ambiental do fornecedor, incluindo o nível de sustentabilidade da exploração pesqueira, manutenção dos recursos pesqueiros e impactos ecológicos da produção.

Nesse ramo de rotulagem ecológica, o Marine Stewardship Council (MSC) é um líder mundial entre os programas de certificação de pesca. Sendo uma organização que desenvolveu um programa independente de rotulagem ecológica criado especificamente para lidar com o problema do esgotamento do estoque de peixes.

Deve-se destacar que a MSC não certifica o produto, mas pescarias inteiras que não contribuem para a pesca predatória ou esgotamento e que mantêm e recuperam estoques saudáveis de peixes; ou que operam de maneira consistente com os ditames do ecossistema; e que são desenvolvidos e mantidos por um sistema de gestão consistente com os aspectos científicos, econômicos e sociais, princípios e normas internacionais, nacionais e locais. 
Um restaurante em Portland, Oregon, denominado O Bamboo Sushi, é um exemplo de um restaurante que optou pelo rótulo ecológico da MSC na indústria do sushi. Estabelecer um programa de rotulagem ecológica para a indústria alimentícia requer a participação voluntária de restaurantes, além da obtenção da confiança do consumidor nesse tipo de programa. Nesse sentido, o "MSC demonstrou a capacidade do programa de proteger esses requisitos e uniu-se com sucesso à indústria de restaurantes para oferecer as mesmas opções sustentáveis, como as oferecidas em muitas lojas ao redor do mundo".

Não resta dúvida de que a bem-sucedida manutenção de pescarias sustentáveis por meio de programas de rótulos ecológicos, como o MSC e o MEL Japão, depende inteiramente da disposição dos consumidores de comprar produtos com essas características. Entretanto, sem demanda suficiente por esse tipo de rotulagem, principalmente sob a alegação de que os custos da verificação de terceiros superam os benefícios da rotulagem ecológica, tais programas não conseguem atingir os padrões de credibilidades desejados. Além disso, quando a demanda por certificação ambiental é alta o suficiente, a certificação voluntaria de terceiros ou o envolvimento governamental se desenvolve.

A ideia de que o atum-rabilho pode desaparecer do cardápio dos restaurantes como consequência do aumento da demanda consumerista por restaurantes sustentáveis, tem lastro na suposição de que o consumidor tem por melhor opção fazer escolhas sustentáveis, a exemplo do que aconteceu com a campanha do atum de golfinhos na década de noventa. Assim, acabar com a pesca predatória pode depender principalmente da preocupação ambiental do consumidor, quando esse desenvolve uma consciência ambiental, principalmente em face de publicidade e campanhas informativas contínuas.

O poder público, por meio de legislação ou de política públicas adequadas deve buscar apoiar as organizações que trabalham com rotulação ecológica, como a MSC, principalmente por meio de estabelecimento de padrões para rotulação e buscando coibir o uso fraudulento ou indevido de programas de sustentabilidade ambiental.

Além do mais, levando-se em conta os níveis potencialmente perigosos de mercúrio contidos no atum-rabilho, além dos elevados riscos de exposição ao mercúrio, a FDA repensa suas recomendações sobre o consumo de atum, esclarecendo aos consumidores o aumento dos riscos de se consumir peixes maiores, como o atum-rabilho. Pode-se utilizar como referência, para se comunicar sobre os potenciais riscos do atum-rabilho, a Preposição 65 da Califórnia, lei de direito ao conhecimento ambiental.

Para aumentar o nível de consciência do consumidor, o poder público deve apoiar as organizações que já estão tomando providências, principalmente, por meio do apoio aos programas de rotulagem ecológica, como o MSC, criando legislações ou políticas públicas que estabeleçam um padrão para rótulos, de forma a garantir sua efetiva aplicação e evitando alegações fraudulentas concernentes à sustentabilidade ambiental.

Além do mais, tendo em conta os níveis potencialmente perigosos de mercúrio contidos no atum-rabilho, e assim os elevados riscos de exposição a tal substância, a exemplo da FDA, o governo brasileiro deve reavaliar suas recomendações para o consumo de atum, deixando claro o aumento do risco de consumir um peixe maior, como o atum-rabilho. Dessa forma, leis de direito ao conhecimento ambiental, como a Proposição 65 da Califórnia, devem ser utilizadas para comunicar os riscos potenciais do atum-rabilho. 


\section{O Código do CONSUMIdor bRASILEIRO E A PROTEÇÃo do ANIMAL NÃO-HUMANO: DESAFIOS E POSSIBILIDADES}

O Código de Defesa do Consumidor (CDC) apesar de ser considerado uns dos mais modernos do mundo na defesa do consumidor em relações de consumo, no que diz respeito aos animais não-humanos segue a mesma linha do artigo 82 do Código Civil brasileiro. Vale dizer, o CDC não faz referência alguma a natureza jurídica dos animais, e também não traz nenhuma norma que lhes dispense um tratamento diferenciado quanto à defesa e proteção.

Sob o ponto de vista da legislação consumerista brasileira os animais não-humanos no trato das relações de consumo que os envolve, havendo algum problema resultante da relação fornecedor/consumidor, nessas hipóteses incidirão na defesa do consumidor os artigos que regem as relações de consumo de coisas ou objetos, inclusive, quanto à troca, devolução e prazos prescricionais provenientes dessas relações.

O Procon São Paulo, em notícia veiculada no site ESTADÃO (ESTADÃO, on line, 2016), confirmou esse entendimento ao orientar os consumidores de animais de estimação dizendo: "Independentemente dos sentimentos que levam as pessoas a adquiri-los, o animal, para fins de enquadramento legal, é equiparado a um bem durável e, por isso, sua aquisição está sujeita às normas do Código de Defesa do Consumidor (CDC)".

Com relação à responsabilidade civil nos casos envolvendo animais não-humanos, da mesma forma incidirá as normas regulamentadoras pertinentes à legislação consumerista, em razão do CDC atribuir aos animais a natureza de bens de consumo duráveis.

Dessa forma, em se tratando de responsabilidade civil quanto à aquisição de animais, esses são considerados bens de consumo e equiparados a bens duráveis, daí, deduz-se que se alguém adquire um animal de estimação doente sem saber, tal, situação será reconhecida como um vício no produto e o consumidor terá que recorrer ao Código do Consumidor para que tenha direito a uma reparação quanto ao dano que lhe fora causado. Uma regra difícil de aceitar, em se tratando de um ser que possui uma vida e sentimentos, mas, a realidade, frente a atual legislação consumerista quanto à proteção que recebe esses seres é a mesma concedida aquela dada a um simples objeto que, porventura, tenha sido adquirido com um defeito de fábrica ou até mesmo um vício oculto, como seria o caso de uma doença que se apresentasse após a compra.

Com efeito, Lisboa, no que diz respeito à responsabilidade pelo vício no produto nesse caso é aquela que:

[...] acarreta prejuízo econômico ao consumidor, pois ele acaba adquirindo ou se utilizando de um bem que não lhe concede a adequação que ordinariamente se poderia esperar, causando-lhe um dano patrimonial. Trata-se como se pode perceber, de mais uma orientação fundamentada no princípio da boa-fé objetiva, como norma geral de conduta, graças à adoção da teoria da confiança contratual por parte do legislador consumerista.

Mas a frente, Lisboa adverte que a responsabilidade pelo vício nesses casos: 
[...] é regulada sob o aspecto de proteção e prevenção contra danos patrimoniais, ou seja, o fornecedor estará incurso na imputação legal a ele atribuída nos arts. 18 a 25 do CDC, sempre que o consumidor (adquirente ou utente destinatário final) vier a sofrer prejuízo econômico puro, ou, ainda, cumulado com ameaça de dano extrapatrimonial, o caso será de responsabilidade pelo fato do produto e serviço, conforme o regime jurídico dos arts. 12 a 17 do CDC).

Contudo, diante de toda essa complexidade que envolve os animais não-humanos e sua natureza jurídica, vale ressaltar, que segundo Azevedo, o Código do Consumidor:

[...] tratou timidamente da questão ambiental, não obstante os interesses dos consumidores e os do meio ambiente possuírem, em não raras situações, a mesma natureza difusa ou transindividual. Com efeito, explica-se o pouco tratamento da matéria ambiental no Código pelo fato de que a ratio legis desse diploma é, em cumprimento ao comando constitucional $\left(\mathrm{CF}\right.$, art. $\left.5^{\circ}, \mathrm{XXXII}\right)$, dar a efetiva proteção ao consumidor como agente econômico no mercado, dotando-o de direitos indisponíveis frente aos fornecedores de produtos e serviços. A questão ambiental surge, assim, como reflexo desse tratamento protetivo.

A explicação para a omissão com relação à proteção dos animais não-humanos, justifica-se em razão de a lei regulamentadora das relações de consumo no Brasil ter como preceito a defesa do consumidor no mercado de consumo. Entretanto, nem por isso a questão ambiental ficou esquecida, como visto nas palavras de Azevedo anteriormente citado, o meio ambiente, mesmo que de forma reflexa recebe por parte da legislação do consumidor proteção.

Ou seja, significa dizer que as possibilidades de os animais não-humanos receberem um tratamento diferenciado de coisas e objetos e, por conseguinte, uma maior proteção, mesmo que de forma reflexa, que lhes assegure direitos fundamentais, como o direito à vida e a liberdade, tem por fundamento o artigo $4^{\circ}$, inciso III do CDC, que diz:

A Política Nacional das Relações de Consumo tem por objetivo o atendimento das necessidades dos consumidores, o respeito à sua dignidade, saúde e segurança, a proteção de seus interesses econômicos, a melhoria da sua qualidade de vida, bem como a transparência e harmonia das relações de consumo, atendidos os seguintes princípios: [...] III - harmonização dos interesses dos participantes das relações de consumo e compatibilização da proteção do consumidor com a necessidade de desenvolvimento econômico e tecnológico de modo a viabilizar os princípios nos quais se funda a ordem econômica (art. 170, da Constituição Federal), sempre com base na boa-fé e equilíbrio nas relações entre consumidores e fornecedores. (Grifo nosso)

Quando o inciso III, do artigo 170 da CF/88 se refere aos princípios nos quais se funda a ordem econômica, não se pode esquecer do inciso VI que diz: "defesa do meio ambiente, inclusive mediante tratamento diferenciado conforme o impacto ambiental dos 
produtos e serviços e de seus processos de elaboração e prestação".

Vê-se que é possível com fundamento nas normas existentes no CDC que os animais não-humanos, como partes integrantes do meio ambiente, esse considerado um direito fundamental de $3^{a}$ geração, possa se estender para além dos humanos, de forma reflexa, direitos fundamentais contidos na Constituição do Brasil de 1988, inclusive, não sendo prima facie descartada a possibilidade de reconhecê-los como sujeitos de direitos.

Ainda, com fundamento no Código de Consumidor, artigo $4^{\circ}$ que diz:

A Política Nacional das Relações de Consumo tem por objetivo o atendimento das necessidades dos consumidores, o respeito à sua dignidade, saúde e segurança, a proteção de seus interesses econômicos, a melhoria da sua qualidade de vida, bem como a transparência e harmonia das relações de consumo, atendidos os seguintes princípios: [...] inciso IV, - educação e informação de fornecedores e consumidores, quanto aos seus direitos e deveres, com vistas à melhoria do mercado de consumo. (Grifo Nosso)

Dessa forma, constitui um direito do consumidor que na embalagem dos produtos que circulam no mercado de consumo brasileiro, conste a informação de que determinado produto exposto na prateleira de um supermercado ou na vitrine de uma loja, ateste que aquele bem ou alimento não é proveniente de experimentos científicos com animais nãohumanos ou sejam de origem proveniente do uso de matéria prima animal.

\section{Conclusão}

A relação animal não-humano vs. humanos tem sido mitigada em decorrência das novas descobertas da neurociência e à luz das teorias expansionistas da ética ambiental não mais é considerada com o mesmo significado que possui a relação homem vs. objeto.

Já está mais do que provado a natureza senciente dos animais vertebrados, o que os torna diferentes de coisas ou objetos.

Os animais não-humanos possuem vida, respiram igual ao homem, são capazes de se locomover e muitos deles desenvolveram inclusive a capacidade de raciocinar e entender alguns comandos emanados pelo homem.

Consideramos que a legislação brasileira infraconstitucional, incluídas o Código Civil e o Código do Consumidor estão fora de contexto no momento contemporâneo em que se preza pela preservação do meio ambiente e no que se refere à natureza jurídica dos animais não-humanos.

É imprescindível que ocorra uma mudança legislativa que inclua os animais nãohumanos em uma nova categoria, retirando-os daquela que os equipara a simples coisas ou objetos. Essa visão antropocêntrica, não mais se concebe diante de todos os fatos que denotam a senciência desses seres vivos. 
É crucial que a sociedade assimile o mais rápido possível o posicionamento das correntes filosóficas expansionistas da ética ambiental e que seja revisto o paradigma antropocentrista atual, que considera apenas o homem como ser possuidor de consciência para que a relação entre humanos e animais não-humanos, assim, considerados como sencientes, seja modificada e lhes seja dispensado um tratamento digno e garantidos direitos fundamentais como o direito à vida, à saúde, à liberdade, a integridade física, dentre outros.

Uma gestão ambiental sustentável com o desenvolvimento de técnicas e ações que definam as atividades do homem visando suprir suas necessidades, sem que seja necessário colocar a prova a integridade do meio ambiente, levando em consideração a sustentabilidade como o suporte que deve se atrelar o desenvolvimento econômico, usando de recursos naturais de forma inteligente e seguindo parâmetros de preservação ambiental já positivados nas leis infraconstitucionais, nos Tratados internacionais e na Constituição do Brasil de 1988, devem ser observados, fiscalizados e sanções aplicadas aos descumpridores dessas regras pelo Poder Público.

São esses os caminhos para garantir a humanidade um desenvolvimento sustentável, com a responsabilidade ambiental como um preceito fundamental que assegura a proteção e a preservação do meio ambiente.

Diante de tantos argumentos e pesquisas científicas é inconcebível nos tempos atuais que os animais, ainda, recebam um tratamento como se fossem simples coisas ou objetos de uso e propriedade do homem em detrimento de seus próprios interesses, apenas visando auferir lucros e por conseguinte expondo os animais a situações de maus-tratos e de extrema crueldade, a exemplo, dos bois e cavalos nas vaquejadas que segundo os defensores de sua prática, seria um esporte já arraigado na cultura do brasileiro, recentemente, considerada pelo STF na ADI 4.983 uma prática cruel que afronta preceitos constitucionais, sendo declarada a inconstitucionalidade da Lei n. 15.299/2013 do Estado do Ceará, que regulamentava a prática como atividade desportiva e cultural.

Com certeza, causa extrema estranheza comparar um ser vivo que respira e dentro do seu corpo bate um coração e que é capaz de sentir emoções, receba um tratamento legal que os enquadre como um "produto de consumo".

É tão absurda a equiparação que, inclusive, não se coaduna com o conceito de produto trazido pelo Código do Consumidor em seu artigo $3^{\circ}, \S 1^{\circ}$ que diz: "Produto é qualquer bem, móvel ou imóvel, material ou imaterial".

Viu-se nesse artigo vários argumentos que são possíveis de mudar a visão antropocentrista que a legislação infraconstitucional ainda traz arraigada em seus termos. A possibilidade de mudanças no Código do Consumidor brasileiro não é uma utopia e um Projeto de Lei para modificar a natureza jurídica dos animais no Código Civil brasileiro já está em trâmite na Comissão de Constituição e Justiça e de Cidadania. De outro lado, a CF/1988 e a Lei 6.938/81 abriram caminhos que possibilitam tais modificações, ao adotarem o conceito do antropocentrismo moderado com relação ao meio ambiente.

Uma excelente ideia e pioneira com relação à proteção do meio ambiente de forma sustentável e inteligente são os selos que ainda não foram criados no Brasil. No entanto, já existem na comunidade internacional e identificam na embalagem dos produtos, aqueles que não foram produzidos por meio de técnicas e experimentos científicos se utilizando de animais ou que tenham sido produzidos a base de matéria prima animal. 
Destes selos, os mais conhecidos são o CRUELTY FREE que significa que determinado produto é "Livre de crueldade" é um selo da Peta, ONG internacional de proteção animal; o LEAPING BUNNY é um selo que traduzindo o nome no Brasil seria chamado de "coelho saltitante", também, atesta que produto e itens da fórmula não foram testados em animais e por fim o CERTIFIED VEGAN um selo vegano, comprova que o produto, além de não testado em bichos, não usa itens de origem animal. (UOL, on line, 2016).

Acreditamos que no Brasil num futuro próximo, os animais não-humanos serão considerados sujeitos de direitos e, consequentemente, terão a garantia da proteção contra a exploração decorrente das atividades econômicas e dos maus-tratos, sendo-lhes assegurados alguns direitos fundamentais atinentes ao homem, ainda, que de forma reflexa, positivados na Constituição Federal do Brasil de 1988.

É de suma importância que os animais não-humanos sejam reconhecidos como possuidores de relevante valor moral e, dessa forma, sejam abolidas o uso abusivo e a exploração pela indústria, comércio, ou seja, pela atividade econômica de uma forma geral.

Não se concebe que o homem, um ser que possui a capacidade de raciocinar superior à de outros animais, até então, os utilizem como um instrumento para malvadeza e ganância humana.

Vivemos atualmente em um Novo Estado Social Democrático de Direito, uma nova era, na qual o meio ambiente é considerado um direito fundamental do homem e como partes integrantes do meio ambiente, os animais não humanos devem ser preservados para que não ocorra a extinção dos espécimes e estejam protegidos contra atos de crueldade e maus-tratos.

Somente dessa forma garantiremos às gerações presentes e futuras um meio ambiente saudável e ecologicamente equilibrado para a segurança e o bem-estar do planeta em que vivemos.

\section{REFERÊNCIAS}

AZEVEDO, Fernando Costa de. O direito do consumidor e a questão ambiental. Disponível em: <http:// www.ambito-juridico.com.br/site/index.php?n_link=revista_artigos_leitura\&artigo_id=6592>. Acesso em: 13 nov. 2016.

AGÊNCIA DE NOTÍCIAS DE DIREITOS ANIMAIS. Mudança da natureza jurídica dos animais segue para a Comissão de Justiça. Disponível em: <http://www.anda.jor.br/07/10/2015/mudanca-natureza-juridicaanimais-segue-comissao-justica>. Acesso em: 13 nov. 2016.

BENJAMIN, Antônio Herman de Vasconcellos e. A responsabilidadecivil pelo dano ambiental no direito brasileiro $e$ as lições do direito comparado. Disponível em: <http://bdjur.stj.jus.br/jspui/bitstream/2011/8632/A_ Responsabilidade_Civil.pdf>. Acesso em: 31 out. 2016.

COSTA, Alberto Neves et al. A Declaração de Cambridge sobre a consciência em animais humanos e não humanos. Revista CFMV, Brasília, v. 19, n. 59, p. 8, jul. 2013.

ESTADÃO ECONOMIA \& NEGÓCIOS. Procon orienta compra de animais de estimação. Disponível em: $\quad<$ http://economia.estadao.com.br/noticias/geral,procon-orienta-compra-de-animais-deestimacao,20020812p12126>. Acesso em: 13 jun. 2016. 
FURLAN, Anderson; FRACALOSSI, William. Direito ambiental. Rio de Janeiro: Forense, 2010.

GOMES, Carla Amado. Direito Ambiental: o ambiente como objeto e os objetos do direito do ambiente. Curitiba: Juruá, 2010.

INSTITUTO ABOLICIONISTA ANIMAL - IAA. Abolicionismo Animal. Disponível em: <http://www. abolicionismoanimal.org.br/interna.php?cod=13>. Acesso em: 02 nov. 2016.

KANT, Immanuel. Fundamentação da Metafísica dos Costumes. Portugal: Edições 70, Lda, 2007.

KATO, Dawn M. Battle for Bluefin: The Consumer's Role in Preserving the Atlantic Bluefin Tuna. California Western International Law Journal, v. 42, 2011, p. 149-188. Disponível em: <http://heinonline. org>. Acesso em: 7 jun. 2018.

LISBOA, Roberto Senise. Responsabilidade civil nas relações de consumo. 3. ed. São Paulo: Saraiva, 2012.

MEDEIROS, Fernanda Luiza Fontoura de. Direito dos Animais. Porto Alegre: Livraria do Advogado, 2013.

MLODINOW, Leonard. Subliminar. Como o inconsciente influencia nossas vidas. Rio de Janeiro: Jorge Zahar Editor Ltda, 2013.

NOTÍCIAS STF. STF julga inconstitucional lei cearense que regulamenta vaquejada. Disponível em: <http:/ / www.stf.jus.br/portal/cms/verNoticiaDetalhe.asp?idConteudo=326838>. Acesso em: 02 nov. 2016.

PET IMAGEM. A Declaração de Cambridge sobre a consciência em animais humanos e não humanos. Disponível em: <http:/ / www.petimagem.com.br/A-Declaracao-de-Cambridge-sobre-a-consciencia-em-animaishumanos-e-nao-humanos.aspx>. Acesso em: 02 nov. 2016.

PETIÇÃO PÚBLICA. Manifesto contra a vaquejada. Disponível em: <http://www.peticaopublica.com. br/pview.aspx?pi=BR91997>. Acesso em: 02 nov. 2016.

STF - ADI-MC 3540. Disponível em: <http://redir.stf.jus.br/paginadorpub/paginador. jsp?docTP=AC\&docID=387260>. Acesso em: 31 out. 2016.

SINGER, Peter. Ética prática. São Paulo: Martins Fontes, 1993.

UOL. Selos Internacionais (O Brasil não tem nenhum). Disponível em: <http:/ / www1.folha.uol.com.br/ fsp/equilibrio/53621-de-olho-na-embalagem.shtml>. Acesso em: 13 nov. 2016.

\section{Notas de Referências (ENDNOTES)}

1. Para maiores detalhes ver ADIN-MC n 3450/DF (BRASIL. SUPREMO TRIBUNAL FEDERAL STF. Medida Cautelar em Ação Direta de Inconstitucionalidade n ${ }^{\circ}$ 3450-DF. Min. Relator: Celso de Mello. Publicado no D.J. em 03.02.2006. Disponível em: <http://redir.stf.jus.br/paginadorpub/ paginador.jsp?docTP=AC\&docID=387260>. Acesso em: 7 jun. 2018.

2. GOMES, Carla Amado. Direito Ambiental: o ambiente como objeto e os objetos do direito do ambiente. Curitiba: Juruá, 2010. p. 15-16 e 18.

3. FURLAN, Anderson; FRACALOSSI, William. Direito ambiental. Rio de Janeiro: Forense, 2010. p. 23-24. 
4. ANTUNES, Paulo de Bessa. Direito ambiental. 10. ed. Rio de Janeiro: Lumen Juris, 2008.

5. BRASIL. SUPREMO TRIBUNAL FEDERAL - STF. ADI-MC 3.540/DF. Rel. Min. Celso de Mello. Disponívelem:<http:/ / redir.stf.jus.br/paginadorpub/ paginador.jsp?docTP=AC\&docID=387260>. Acesso em: 23 maio 2018.

6. KANT, Immanuel. Fundamentação da Metafísica dos Costumes. Portugal: Edições 70, Lda, 2007. p. 6669.

7. MEDEIROS, Fernanda Luiza Fontoura de. Direito dos Animais. Porto Alegre: Livraria do Advogado, 2013. p. 34.

8. COSTA, Alberto Neves et al. A Declaração de Cambridge sobre a consciência em animais humanos e não humanos. Revista CFMV, Brasília, v. 19, n. 59, p. 8, jul. 2013. p.8.

9. COSTA, Alberto Neves et al, op. cit., p.8.

10. MLODINOW, Leonard. Subliminar. Como o inconsciente influencia nossas vidas. Rio de Janeiro: Jorge Zahar Editor Ltda, 2013. p. 76.

11. MLODINOW, Leonard, op.cit., p. 81.

12. ESTADÃO. Caderno de Economia e Negócios. Procon orienta compra de animais de estimação. Disponível em: <https://economia.estadao.com.br/noticias/geral,procon-orienta-compra-deanimais-de-estimacao,20020812p12126>. Acesso em: 23 maio de 2018.

13. SUPREMO TRIBUNAL FEDERAL - STF. ADI-MC 3.540/DF. Rel. Min. Celso de Mello. Disponível em: <http://redir.stf.jus.br/paginadorpub/paginador.jsp?docTP=AC\&docID=387260>. Acesso em: 23 maio 2018.

14. INSTITUTO ABOLICIONISTA ANIMAL - IAA. Abolicionismo Animal. 2016. Disponível em: <www. abolicionismoanimal.org.br/interna.php?cod=13>. Acesso em: 6 jun. 2018.

15. INSTITUTO ABOLICIONISTA ANIMAL - IAA. Abolicionismo Animal. 2016. Disponível em: <www. abolicionismoanimal.org.br/interna.php?cod=13>. Acesso em: 6 jun. 2018.

16. SINGER, Peter. Ética prática. São Paulo: Martins Fontes, 1993. p. 22.

17. SINGER, Peter, op. cit., p. 65.

18. SINGER, Peter, op. cit., p. 72.

19. SINGER, Peter, op. cit., p. 75.

20. BRASIL. Ministério do Meio Ambiente - MME. Instituto Brasileiro do Meio Ambiente e dos Recursos Naturais Renováveis - IBAMA. Disponível em: <http://www.ibama.gov.br/>. Acesso em: 7 jun. 2018.

21. Convém esclarecer que o atum-rabilho do Atlântico é um dos maiores peixes do mundo. Quando totalmente crescido, este peixe magnífico pode atingir comprimentos de $4 \mathrm{~m}$ e pesar mil e quinhentas quilos. Este peixe de sangue quente pode nadar em velocidades extremamente rápidas e tem uma 
vida útil natural de mais de vinte anos. Existem três espécies principais de atum-rabilho: o atumrabilho do sul, o atum-rabilho do Pacífico e o atum-rabilho do Atlântico. Todas as três espécies estão sendo pescadas predatoriamente para atender à demanda imediata [...]. A conservação de cada espécie é supervisionada por organizações regionais de gestão pesqueira em todo o mundo.

22. KATO, Dawn M. Battle for Bluefin: The Consumer's Role in Preserving the Atlantic Bluefin Tuna. California Western International Law Journal, v. 42, 2011, p. 149-188. Disponível em: < http:/ / heinonline. org >. Acesso em: 7 jun. 2018. p. 151. (Tradução livre).

23. KATO, Dawn M. Battle for Bluefin: The Consumer's Role in Preserving the Atlantic Bluefin Tuna. California Western International Law Journal, v. 42, 2011, p. 149-188. Disponível em: < http:/ / heinonline. org>. Acesso em: 7 jun. 2018. p. 151. (Tradução livre).

24. KATO, Dawn M. Battle for Bluefin: The Consumer's Role in Preserving the Atlantic Bluefin Tuna. California Western International Law Journal, v. 42, 2011, p. 149-188. Disponível em: <http:/ / heinonline. org>. Acesso em: 7 jun. 2018. p. 151. (Tradução livre).

25. KATO, Dawn M. Battle for Bluefin: The Consumer's Role in Preserving the Atlantic Bluefin Tuna. California Western International Law Journal, v. 42, 2011, p. 149-188. Disponível em: < http:/ / heinonline. org>. Acesso em: 7 jun. 2018. p. 161. (Tradução livre).

26. BRASIL. Ministério do Meio Ambiente. Espécies Ameaçadas. Disponível em: <http://www.mma. gov.br/informma/item/886>. Acesso em: 25 maio 2018. Referida Convenção conta com mais de 130 Estados-Membros, incluindo o Brasil, que o ratificou em novembro de 1975 e abrange hoje cerca de 30.000 espécies da fauna e flora selvagens e, desde a sua adoção, não houve notificação de extinção decorrente do comércio internacional de qualquer das espécies incluídas.

27. KATO, Dawn M. op. cit., p. 153.

28. KATO, Dawn M. Battle for Bluefin: The Consumer's Role in Preserving the Atlantic Bluefin Tuna. California Western International Law Journal, v. 42, 2011, p. 149-188. Disponível em: <http:/ / heinonline. org>. Acesso em: 7 jun. 2018.

29. Idem, ibidem.

30. KATO, Dawn M. Battle for Bluefin: The Consumer's Role in Preserving the Atlantic Bluefin Tuna. California Western International Law Journal, v. 42, 2011, p. 149-188. Disponível em: <http:/ / heinonline. org>. Acesso em: 7 jun. 2018.

31. KATO, Dawn M. Battle for Bluefin: The Consumer's Role in Preserving the Atlantic Bluefin Tuna. California Western International Law Journal, v. 42, 2011, p. 149-188. Disponível em: <http:/ / heinonline. org>. Acesso em: 7 jun. 2018.

32. KATO, Dawn M. Battle for Bluefin: The Consumer's Role in Preserving the Atlantic Bluefin Tuna. California Western International Law Journal, v. 42, 2011, p. 149-188. Disponível em: <http:/ / heinonline. org>. Acesso em: 7 jun. 2018.

33. Art. 82. São móveis os bens suscetíveis de movimento próprio, ou de remoção por força alheia, sem alteração da substância ou da destinação econômico-social. 
34. LISBOA, Roberto Senise. Responsabilidade civil nas relações de consumo. 3. ed. São Paulo: Saraiva, 2012. p. 401-402.

35. LISBOA, Roberto Senise. Responsabilidade civil nas relações de consumo. 3. ed. São Paulo: Saraiva, 2012. p. 402.

36. AZEVEDO, Fernando Costa de. O direito do consumidor e a questão ambiental. Disponível em: <http:// www.ambito-juridico.com.br/site/index.php?n_link=revista_artigos_leitura\&artigo_id=6592>. Acesso em: 13 nov. 2016.

37. AZEVEDO, Fernando Costa de. O direito do consumidor e a questão ambiental. Disponível em: <http:// www.ambito-juridico.com.br/site/index.php?n_link=revista_artigos_leitura\&artigo_id=6592>. Acesso em: 13 nov. 2016. 